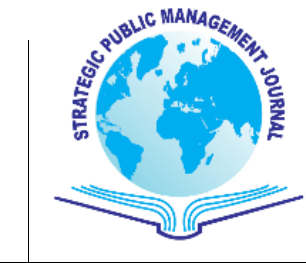

\section{Social Media, Changing Culture, And Policymaking}

\author{
Sosyal Medya, Değişen Kültür ve Politika Belirleme
}

Mehtap KANDARA ${ }^{1}$

Hicran HAMZA CELİKYAY ${ }^{2}$
Strategic Public Management Journal

Volume 3, Issue 6, pp. 105-115 DOI: $10.25069 /$ spmj.358058

Received: 26.11.2017

Accepted: 27.12 .2017

(c) The Author(s) 2017

For reprints and permissions: http://dergipark.gov.tr/spmj

\begin{abstract}
Social media is the new deal and it has changed the way we do communicate with one another. Before people were restrained by space and time but now there are no physical boundaries; social media networks are virtually global; people using the same platform share ideas from all over the world instantaneously. Social media is being used to motivate and organize masses and help them act as one body. It is therefore essential for policymakers to understand the importance of social media and use it effectively at all times, more so during times of distress, to reach out to public and provide correct information as public is being bombarded with misinformation.
\end{abstract}

Key Words: Social media, policymaking, cultural change, politics, social change

\title{
INTRODUCTION
}

Social media is the new deal and it has changed the way we do communicate with one another. Before people were restrained by space and time but now there are no physical boundaries; social media networks are virtually global; people using the same platform share ideas from all over the world instantaneously. People use social media to express their political opinions, follow elections, and raise their concerns with the election results. Since the "Arab Spring" in early 2011, social media's role has been realized in making a political change in authoritarian regimes. There is a joke that has been circulating via social media since the resignation of President Mubarak on February 11, 2011.

Hosni Mubarak, Anwar Sadat, and Gamal Abdel Nasser are having tea in the afterlife. Mubarak asks Nasser, "How did you end up here?" "Poison," Nasser answers. Mubarak then turns to Sadat. "What about you?" he asks. "An assassin's bullet," Sadat says. Sadat and

\footnotetext{
${ }^{1}$ Dr., Southern University and A\&M College, Nelson Mandela College of Government and Social Sciences, Department of Public Policy, Baton Rouge, Louisiana, mehtap_kandara_00@subr.edu

${ }^{2}$ Dr., Istanbul Metropolitan Municipality, hicran.celikyay@ibb.gov.tr
} 


\section{Nasser then turn to Mubarak, "And you?" To which Mubarak replies: "Facebook." (Lim,} 2012: 231)

Even though there are skeptics about the role of social media in the Arab uprising, majority of the literature give credit to social media for organizing and motivating masses that were leaderless yet acted collectively during the uprising movement against authoritarian regimes in the Middle East and North African region. Following the Arab Spring, Western democracies were pleased with their freedoms, democracy, and civil obedience. All of a sudden, the same social media started to move masses in these democratic countries to protest against the actions of their governments. "Occupy Wallstreet" was one of these movements. All of a sudden, all manner of social unrest erupted in normally peaceful cities, again orchestrated and enabled by social media, this time in democratic countries. Sometimes, these protests got out of hand, turned into violence, and destruction erupted as masses made demands to be met by the current administration. The protestors demanded the democratically elected governments to step down in order to end riots such as in summer 2013 protests in Turkey. A democratic government cannot let masses of protestors to highjack democracy but at the same time need to understand how the social media affects the whole process and respond accordingly and yet democratically. Social media is not going away anytime soon therefore it is time that the leaders of the democratic nations need to understand how social media works and respond accordingly during the time of crisis. They need to draft and implement social media policies with a clear understanding of the social media dynamics and allow citizens to express their ideas freely yet at the same time protect the nation from the ills and evils of the social media.

\section{CHANGING CULTURE: FROM SUBSTANCE TO PUNCH LINES}

From Civil War to early $21^{\text {st }}$ century, the means of learning about current events changed gradually and dramatically. Earlier in American history, not only did most Americans learn about current events through reading, but they also had high literacy rates (Dunn, 2007: 76). According to Postman, between 1640 and 1700, the literacy rate for men in Massachusetts and Connecticut was between 89 and 95 percent. Average Americans today find the Federalist Papers difficult to read, but back in 1787, the average Americans read them throughout all parts of the nation (Postman, 1985: 33).

Many foreign observers not only notice a high level of literacy but also its influence on other means of communication such as simple daily conversation style that was influence by the structure of the printed word. Back then reading was so universal because it was the source of information. Substance and ideas rather than style and image were the focus of this reading-saturated society, which had no televisions, telegraphs, or even photographs. People learned about the events of the day mostly through reading (Dunn, 2007: 77). Public formed judgment about presidents and presidential candidates mostly through their writings, not through their pictures and images. Back then, most people wouldn't have noticed the president if they saw them in the street yet they would have been able to articulate about the political views of the same president. The mental and physical requirements of a reading-saturated society help to produce a substance-oriented culture.

This is so much different from American society today. Reading no longer functions as the main gateway to information for many. Nearly half of adults read poorly. So, people no longer rely on reading to gain information about the current events and the world they live in. Instead, they rely on television and the Internet (Dunn, 2007: 78). With conventional means of media (newspapers, television), the author or the speaker is known and the information flow is in one direction allowing audiences only to consume 
information. The Internet, social media in particular, accommodates multi-directional information flow, allowing users to communicate with one another (Himelboim, Lariscy, Tinkham, \&Sweetser, 2012: 94). Comments, news, tweets could be shared anonymously.

In recent years, social media emerged as a popular medium especially by younger generation for providing new sources of information and rapid communications. Twitter that allows users to broadcast tweets of up to 140 characters to an audience of followers using the web or mobile devices. With Twitter and other social media punch lines "substituted" substance.

\section{SOCIAL MEDIA}

Howard and Parks (2012: 359) defines social media in three parts, consisting of (1) the information infrastructure and tools used to produce and distribute contents; (2) the content that takes the digital form of personal messages, news, ideas, and cultural products; and (3) the people, organizations, and industries that produce and consume digital content.

New technology has changed traditional media outlets from one-way communication-from content producer to consumer- to multiple lines of communications. Boczkowski describes the shift from gatekeeping to gate opening, or opening up editorial content to people outside the staff of the media outlet. This develops the role of a media outlet as a voice of the community, creating "new engagements between media organizations and consumers who contribute to the production process while making a living some other way." This potentially allows voices to be heard that were previously ignored, particularly minorities (Bali \& Bossone, 2012: 23).

Social media platforms are utilized extensively by activists in a variety of political systems. Their role in the evolution of events during the "Arab Spring" has been widely discussed by the literature (Etling, Faris \& Palfrey 2010, Howard, Agarwal \& Hussain 2011, Tufekci \& Wilson 2012, Youmans \& York 2012, Papacharissi \& Oliveira 2012, Thompson 2012, Travis 2013) but it is also important to recognize that social media is used to serve the political goals of reformers, revolutionaries, and authoritarian regimes (Youmans \& York, 2012: 315). The Internet in Egypt was quickly utilized for dissent by liberals, minorities, religious groups, and others opposed to the authoritarian Mubarak regime. The online political sphere emerged first in the form of blogs and personal sites, later in Facebook, YouTube, and Twitter. During the protests, protestors steadily produced and disseminated content in real time. The shutdown of Internet service between January 25 and February 2 slowed, but did not stop, the flow of information out of Tahrir Square, as a small but technologically savvy group of protestors continued to disseminate information and videos. Al-Jazeera was also focused on the events on Egypt, often replaying videos obtained through social media. After eighteen days of sustained protests, Mubarak announced his resignation on February 11. (Tufekci \& Wilson, 2012: 364).

However, the Internet has also allowed malicious groups to promote their ideas globally as well. White supremacy, racist, anti-Semitic, anti-Islam, and other malicious groups found a free platform to share and spread their ideas and even organize and plan illegal activities that initially start online and eventually move to the streets. In June 2013, a judge has sentenced an Alabama man to a year in federal prison for tweeting a threat against President Obama. Prosecutors say Javis Britton sent a tweet in September that said, "Let's kill the president. F.E.A.R." Several people have been connected to a national militia group that prosecutors say was called F.E.A.R. - Forever Enduring Always Ready. They said the group had terrorism plans and 
an ultimate goal to overthrow the U.S. government and assassinate the president (USA TODAY 2013, Huffington Post 2013).

Papacharissi and Oliveira findings regarding the influence of social media in the Egyptian revolution of 2011 carry important implications for the interplay between social networking sites like Twitter and Facebook, journalism, and political engagement. First, news feeds collectively generated by citizens, bloggers, activists, journalists, and media outlets expose the temporal incompatibilities between live tweeting news and traditional news reporting. Tweets achieve the drama on the spot, which is compelling and engaging for readers, but not necessarily compatible with fact checking processes of western paradigms of journalism. Second finding contradicts with the assumption that movements utilizing social media are somehow leaderless. \#Egypt was energized by several key bloggers, activists, and informed citizens who turned to social network platforms because other forms of opinion expression were not as accessible, under surveillance, or otherwise heavily regulated. Digital platforms do not rob movements of their leaders. But they do permit a distributed or "crowdsourced" form of leadership based on mechanisms that reward those more involved. Third, the results of their study underscore the need to consider affect in explanations of the role of media use during mobilization. Combined with the networked and always on character of social media, the affective aspects of messages nurture and sustain involvement, connection, and cohesion. Previous studies have emphasized the role of sharedtopics, interests and geo-locality. They extend this work by advancing the concept of affective news streams, to describe how news is collaboratively constructed out of subjective experience, opinion, and emotion within an ambient news environment (Papacharissi \& Oliveira, 2012: 279).

One common characteristic of social media sites is that they are mostly free and therefore widely accessible among different socioeconomic classes. Even in the developing countries, access to the Internet is becoming widely available. With the advancement of mobile phones with Internet capabilities, access to social media became instantaneous.

\section{SKEPTICS AND SUPPORTERS OF THE POWER OF SOCIAL MEDIA IN SOCIAL AND POLITICAL CHANGE}

Malcolm Gladwell is a prominent skeptic of the importance of social media in progressive social and political change. In an October 2010 article in the New Yorker, he argues that real social change is brought about by high-risk meaningful activism, pointing to a number of famous examples: the 1960s sit-ins by black college students in Greensboro, North Carolina; the year-long Montgomery bus boycott organized by Martin Luther King, Jr. in 1955 and 1956; and Australia's indigenous "Freedom Ride" and the "Green Bans." According to Gladwell, such movements are characterized by strong group identity and cohesion with strong ties. Gladwell argues that social media connections promote weak ties and low-risk activism, or "slacktivism." He argues that "liking" something on Facebook, or retweeting a story, requires little effort, yet those actions might lead the user into thinking they are doing something meaningful. Gladwell caustically notes that "Facebook activism succeeds not by motivating people to make a real sacrifice but by motivating them to do the things people do when they're not motivated enough to make a real sacrifice." He also argues that social media creates loose and leaderless networks that are not capable of organizing revolutions. Evgeny Morozov points out the danger that the sheer volume of information available through social media — coupled with its increased general availability via the Internet and 24/7 news cycles — creates shorter attention spans in which important news is quickly supplanted by new developments elsewhere. 
While social media may create quicker and louder conversations, those conversations may tend to be shallow, short, and easily displaced by the newest big thing (Joseph, 2012: 150).

Not all commentators share Gladwell's skepticism of the power of social media. New York University media professor Clay Shirky believes that social media is an important new tool for promoting social and political change. In his article titled "The Political Power of Social Media", in January 2011 before the Arab Spring, he cited a number of examples where social media was the catalyst for significant political change, such as Moldova's Communist Party losing power in 2009 when massive protests coordinated in part by text message, Facebook, and Twitter. Shirky argues that "political freedom has to be accompanied by a civil society literate enough and densely connected enough to discuss the issues presented to the public." (Shirky, 2011: 19). He endorses the theory of sociologists Elihu Katz and Paul Lazars felt that the formation of well-considered political opinions is a two-step process. The first step requires access to information; the second, use of that information in conversation and debate. Under this framework, Shirky argues that social media drastically changed how people form political opinions and made information widely accessible that people more than ever are able to construct their points of view (Joseph, 2012: 152).

What role has social media played in the Arab Spring? Surely social media alone did not cause the revolution and the demonstrations. The underlying cause of the uprisings was mass dissatisfaction with corrupt and oppressive systems of government and growing gaps between the rich and the poor. Skyrocketing food costs, which was caused by global conditions rather than local economic incompetence, deepened dissatisfaction (Joseph, 2012: 157).

\section{POLICYMAKING: CENSORSHIP VS SURVEILLANCE}

According to Shirky, social media have become coordinating tools for most of the world's political movements, just as most of the world's authoritarian governments (and, alarmingly, an increasing number of democratic ones) are trying to limit access to it. In response, the U.S. State Department has committed itself to "Internet freedom" as a specific policy aim. Arguing for the right of people to use the Internet freely is an appropriate policy for the United States, both because it aligns with the strategic goal of strengthening civil society worldwide and because it resonates with American beliefs about freedom of expression. In January 2010, U.S. Secretary of State Hillary Clinton outlined how the United States would promote Internet freedom abroad. She emphasized several kinds of freedom, including the freedom to access information (such as the ability to use Wikipedia and Google inside Iran), the freedom of ordinary citizens to produce their own public media (such as the rights of Burmese activists to blog), and the freedom of citizens to converse with one another (such as the Chinese public's capacity to use instant messaging without interference). Clinton announced funding for the development of tools designed to reopen access to the Internet in countries that restrict it. This "instrumental" approach to Internet freedom concentrates on preventing states from censoring outside Web sites, such as Google, YouTube, or that of The New York Times. It focuses only secondarily on public speech by citizens and least of all on private or social uses of digital media. According to this vision, Washington can and should deliver rapid, directed responses to censorship by authoritarian regimes (Shirky, 2011: 29-30).

Despite the stated goal, there have been hiccups in the implementation of Clinton's plan. For example, a major blunder occurred when the United States planned to facilitate the export of Haystack, technology that was supposed to circumvent censorship and protect privacy. The technology, however, turned out not to be so secure; users that installed the technology in places like Iran would have been put in considerable peril. 
Furthermore, other aspects of U.S. foreign policy undermine its stated goal of facilitating global Internet freedom. Its sanctions on Iran, for example, obstruct the ability of American companies to provide important information systems in that country. Ironically, the U.S. government's call to Twitter to maintain its connections in Iran during the uprising of mid-2009 was probably a call to Twitter to continue breaking U.S. sanctions. Thus, U.S. policy in this area is not particularly coherent. Morozov believes that Clinton's 2010 speech backfired. It alarmed rival regimes by suggesting that the Internet was not simply a forum for free speech but a foreign policy tool of the United States. These regimes, such as Russia, reacted accordingly by clamping down harder on Internet freedoms. Iran announced its plan to launch its own "Halal Internet" in late 2012, which will be extensively censored in accordance with its government's views of Islamic morality and its own "security" needs. Iran plans to offer this service to Islamic neighbors (Joseph, 2012: 171).

A key concern regarding the value of social media to political change is the extent to which the relevant sites are censored. While we assume that social media facilitates interaction between users sharing content, the fact is that the content is mediated through, and can be suppressed by a private intermediary. Two issues arise regarding censorship policies: (1) The extent to which a company assents to local censorship laws in order to conduct business in a particular State, and (2) the content imposed by companies themselves. The first issue is particularly prominent with regard to Internet companies doing business in China. Internet companies that operate in China must comply with the country's strict censorship rules, or be banished outside its firewall, which means that content is either inaccessible or slow to upload, and therefore less likely to be accessed. Although the issue of business acquiescence in State censorship receives more attention, company-imposed censorship is potentially more pernicious in undermining progressive social movements. In States that respect the rule of law, one might be able to successfully challenge a State's censorship of material in court. By contrast, there are few official remedies available if Facebook chooses to take one's page down: it is, after all, Facebook's platform. Facebook's Statement of Rights and Responsibilities provides that its users cannot "post content that: is hateful, threatening, or pornographic; incites violence; or contains nudity or graphic or gratuitous violence," or that is "unlawful, misleading, malicious, or discriminatory." These rules sound reasonable, except that Facebook reserves the right to remove content if it "believes that it violates [the] Statement." On April 29, 2011, Facebook was accused of "purging" activist accounts in the United Kingdom when it suddenly removed dozens of pages that challenged a variety of government policies. Facebook also found itself mired in controversy over its initial refusal, and then acquiescence to, a request by the Israeli government to remove a page promoting a Third Intifada in the Occupied Territories, on the grounds that the page promoted violence against Jews. From a human rights perspective, there is certainly nothing illegitimate about Facebook being used to promote peaceful protests in the Occupied Territories, just as it has been used to promote protests in other parts of the Middle East and the world (Joseph, 2012: 179).

After a decade and a half of ongoing contentious debate over content regulation in the United States, we are still very far from reaching political consensus on the acceptable limits of free speech and the best means of protecting minors and policing illegal activities on the Internet. Many government-mandated attempts to regulate content have been barred on First Amendment grounds, often after lengthy legal battles. However, the Unite States government has been able to exert pressure indirectly where it cannot directly censor. U.S. content restrictions tend to rely more on the removal of content than blocking. In contrast to much of the world, where internet service providers (ISPs) are subject to state mandates, most content regulation in the United States occurs at the private level. 
Although the First Amendment has been used over and over again to block Internet regulations, concerns related to national security in the Unites States have contributed to the development of an extensive and technologically sophisticated online surveillance system. The U.S. surveillance system was expanded significantly under the Bush administration following the attacks of September 11, 2001. Government wiretaps are reported to have included taps on major Internet interconnect points and data mining of Internet communications. Tapping these interconnect points would give the government the ability to intercept every overseas communication and many domestic ones. The U.S. government has moved to dismiss lawsuits filed against it and against AT\&T by asserting the state secrets privilege; district courts in California and Michigan have refused to dismiss the lawsuits. If the allegations prove to be true, they show that the United States maintains the world's most sophisticated Internet surveillance regime. During Barack Obama's election campaign, he criticized both the Bush administration's use of warrantless surveillance and its reliance on the state secret privilege, yet in January 2009 defended congressional legislation immunizing telecommunications companies from lawsuits regarding their participation in the Bush administration's surveillance programs. The U.S. government is required to produce annual reports on the number of wiretaps it conducts under Title III of the Omnibus Safe Streets and Crime Control Act of 1968 (the "Wiretap Act"), as well as communication interceptions conducted under the Foreign Intelligence Surveillance Act and the Pen Register and Trap and Trace statute. No reports have been provided under the Pen/Trap statute since 1998 (Deibert, Palfrey, Rohozinski, \&Zittrain, 2010: 381).

There are different ways nations censor the use of social media by their citizens, shutting off the social media altogether is something that rarely happens. However, it happens at the most politically sensitive times and has widespread - if not global - consequences for political, economical and cultural life. Research conducted by Howard, Agarwal, and Hussain which covers the period 1995-2011 builds a grounded typology on the basis of regime type, what states actually did to interfere with digital networks, why they did it, and who was affected. According to this research, both democratic and authoritarian regimes disable social media networks for citing concerns about national security, protecting authority figures, and preserving cultural and religious morals (Howard, Agarwal, \& Hussain, 2011: 216).

States interfere with digital networks using many tactics, with various levels of severity: online, by shutting down political websites or portals; offline, by arresting journalists, bloggers, activists, and citizens; by proxy, through controlling ISPs, forcing companies to shut down specific websites or deny access to entire online and mobile networks. Surprisingly, the study found that while authoritarian regimes practice controlling full-networks, sub-networks, and nodes more than democracies, democracies are the most likely to target civil society actors by proxy by manipulating ISPs. The most extreme form of network control is when the state shut down access to the Internet. Authoritarian regimes shut down access to the Internet twice as more as democracies. Unlike the most extreme measure of shutting down entire online networks, states are most likely to target individual websites or their producers and users. Democracies are much more likely to engage in online content censorship than other tactics, although they also frequently target members of civil society offline. When unable to block online content effectively, states are forced to go directly towards censoring individuals. Authoritarian states do this most often, and in many cases, with more severity (Howard, Agarwal, \& Hussain, 2011: 222).

\section{THE OTHER SIDE OF THE COIN}

Social media can be used to communicate misinformation as readily as it can be used to convey reliable information. For example, "A Gay Girl in Damascus", Amina Arrat, was one of the more popular Syrian 
bloggers in the beginnings of the uprising, blogging about revolution, sexuality, and repression in Syria. The story fell apart after "Amina" was revealed to be Tom McMaster, a masters student residing in Scotland. The unmasking of Amina as a straight man from Scotland reminded us all how easy it can be to spread lies and use a false identity over the internet. It also no doubt undermined the real Syrian activist bloggers and its receptive audience (Joseph, 2012: 172).

Papacharissi and Oliveira developed a novel category of affective news to describe the peculiar kinds of content that circulate most easily over social media during political crisis: some gossip, some facts, plenty of opinion. We should not therefore assume that social media automatically democratizing or that the political discussion they engender is necessarily in line with idealized conceptions of civic discourse (Howard, 2012, Papacharissi\& Oliveira, 2012).

Right after the Arab Spring, just as Western democracies were congratulating themselves on their freedoms and civil obedience, all manner of social unrest erupted in normally peaceful cities, again orchestrated and enabled by social media. After the city's beloved Canucks lost the final game of ice hockey's Stanley Cup to the Boston Bruins, disgruntled Vancouver fans took to the streets and caused millions of dollars worth of damage to one of the world's most livable cities. Drunken rioters tweeted on their smartphones and took photographs of themselves and others that were then posted on Facebook. Ironically, these messages and images provided easy evidence for their later identification and ample proof for police to be able to charge them.Many faced 'trial by Facebook' as other users set up Facebook pages that allowed members of the social network to identify the guilty parties and hurl invective at them. The riots in London and other British cities were largely orchestrated by individuals using the instant messaging service on their Blackberries. Subsequently, dozens of Facebook pages appeared expressing concern for the damage and celebrating the charges subsequently brought on rioters. Occupy Wallstreet movement was, and is, orchestrated by a plethora of social media, including YouTube videos, blogs, Facebook pages, and Twitter feeds, mostly on devices made by the very corporations the members of the movement target (Pitt, 2012: 105-106).

Social media platforms are neutral tools that can be used to promote both good and bad causes. Of course, the traditional pro-speech argument suggests that in the free market of ideas, "bad" speech can be drowned out by "good" speech. Such a statement may seem trite and its premise cannot be proven, but the opposite cannot be proven, either. At the very least, social media increases participation; but greater participation does not necessarily lead to democracy and pluralism. It depends on "the values people bring to the table" (Joseph, 2012:174).

\section{SOCIAL MEDIA USE DURING JULY 15 COUP ATTEMPT IN TURKEY}

July 15 coup attempt in Turkey has been an historical event not only for Turkey and its people, but also for the region, and the world at large (Ataman \&Shkurti, 2016: 51). In the midst of military bombings, barricades, and bloodshed, a large group of citizens came together, showing a sense of solidarity and pride in their country that defied fear and violence. That night political parties didn't matter. What mattered was protecting the country from a group that most Turkish Citizens didn't believe represented their best interest (Houston, 2016). Western media reported the escalating siege and its aftermath swayed with their biases, stereotypes, and misunderstanding. Even after the failed coup attempt, instead of condemning the attack on democracy, Western media continued to blame the tens of thousands that filled the streets that night to protect their country from a group of traitors within the military and the police force (Houston, 2016; Ataman \& Shkurti, 2016). As the coup was in progress, the former CIA official Bob Baer told CNN anchor 
Anderson Cooper that the Turkish coup was "not professionally done... They should have taken CNN Turk and closed it down the first minutes, the radio station, social media, the internet. Even if they didn't arrest [Turkish President Recep Tayyip] Erdogan, they should have taken care of all of that right at the beginning" (Marans, 2016). Indeed, on July 16, 2016 at 00:03, military took over the state-run news channel TRT and their broadcasting was interrupted and a news reporter was forced to read a pre-prepared statement saying the military supposedly fully ceased control to protect the democratic order. Turkish privately-owned news channel CNN Turk was briefly halted during a live broadcast as the soldiers enter the studio control room. Twenty-three minutes after TRT take-over, at 00:26, President Recep Tayyip Erdogan Face Timed CNN Turk reporter, Hande Firat, to address the nation live on TV. His speech motivated thousands - regardless of their political affiliation - to run to the streets and fight against the opposing group within the Turkish military. Shortly after his CNN Turk FaceTime connection, he sent a tweet calling the public to fill the streets and the airports to protect their democracy and National will. Other government agencies and officials effectively used social media to motivate and organized the masses against the military coup attempt (Devran \& Ozcan, 2016: 82). The effective use of social media helps organize the public to resist the coup attempt.

\section{CONCLUSION}

The social media does not seem to be disappearing anytime soon. None of the social media portals were originally designed for collecting or disseminating information on politics or public affairs. Yet, it has been motivating and organizing many social movements. The policy challenge that the policymakers are facing will continue in the United States mostly due to the First Amendment. Social media firms will continue to limit anonymity, prohibit certain content, and depend on community policing while at the same time government undoubtedly will seek to increase leverage against social media providers, and ISPs and pursue strategies of infiltration and surveillance. During times of crisis, democratic governments cannot let masses of protestors to highjack democracy but at the same time need to understand how the social media affects the whole process and respond accordingly and yet democratically. Social media is being used to motivate and organize masses and help them act as one body. It is therefore essential for policymakers to understand the importance of social media and use it effectively at all times, more so during times of distress, to reach out to public and provide correct information as public is being bombarded with misinformation. Policymakers need to understand the culture of social media and put in place effective social media policies.

\section{REFERENCES}

Ala. man sentenced for tweeted Obama threat. (2013, June 20). USA TODAY. Retrieved from http://www.usatoday.com/story/news/nation/2013/06/20/tweeted-obama-threat/2442689/ on July 20, 2013.

Ataman, M., \&Shkurti, G. (2016). BATININ DARBE SICIILI VE 15 TEMMUZ DARBE GİRIŞIMINE TEPKİSİ. Adam Academy Journal of Social Sciences/Adam Akademi Sosyal Bilimler Dergisi, 6(2).

Bali, M., \&Bossone, A. (2012). Intercultural and Multicultural Education in Universities and Media Studies: A Comparison of Two Programs Implemented at the American University in Cairo. In Aktay, Y., El-Sharkawy, P., \&Uysal, A. Culture and Politics in the New Middle East. Institute of Strategic Thinking. Ankara: Oncu.

Deibert, R.J., Palfrey, J.G., Rohozinski, R., \&Zittrain, J. (2010). Access Controlled: The Shaping of Power, Rights, and Rule in Cyberspace. Cambridge, MA: MIT Press. 
DEVRAN, Y., \& ÖZCAN, Ö. F. (2016). 15 Temmuz Darbe Girişimi: Gelenekselden Yeniye Medya Araçlarının Kullanımı. AJIT-e: Online Academic Journal of Information Technology, 7(25).

Dunn, C.W. (2007). The Seven Laws of Presidential Leadership: An Introduction to the American Presidency. New Jersey: NJ: Pearson Prentice Hall.

Etling, B., Faris, R., and Palfrey, J. G. (December 9, 2010) Political Change in the Digital Age: The Fragility and Promise of Online Organizing. Berkman Center Research Publication No. 2010-15. Available at SSRN: http://ssrn.com/abstract=1871316

Himelboim, I., Lariscy, R., Tinkham, S. F., \&Sweetser, K. D. (2012). Social Media and Online Political Communication: The Role of Interpersonal Informational Trust and Openness. Journal of Broadcasting \& Electronic Media, 56(1), 92-115.

Houston, S. (2016, August 26). The Coup Attempt as Told by the West. Research Turkey: Centre for Policy and Research on Turkey. Retrieved from http://researchturkey.org/the-coup-attempt-as-told-by-the-west/ on May 27, 2017.

Howard, P. N., Agarwal, S. D., \& Hussain, M. M. (2011). When Do States Disconnect Their Digital Networks? Regime Responses to the Political Uses of Social Media. Communication Review, 14(3), 216232.

Howard, P. N., \& Parks, M. R. (2012). Social Media and Political Change: Capacity, Constraint, and Consequence. Journal of Communication, 62(2), 359-362.

Jarvis Britton, Alabama Man, Pleads Guilty to Tweeting Obama Threats. (2013, March 18). HuffingtonPost. Retrieved from http://www.huffingtonpost.com/2013/03/18/jarvis-britton-alabamaobama_n_2901569.html on July 20, 2013.

Joseph, S. (2012). SOCIAL MEDIA, POLITICAL CHANGE, AND HUMAN RIGHTS. Boston College International \& Comparative Law Review, 35(1), 145-188.

Lim, M. (2012). Clicks, Cabs, and Coffee Houses: Social Media and Oppositional Movements in Egypt, 2004-2011. Journal of Communication, 62(2), 231-248.

Marans, Daniel (2016, July 16), Former CIA Officials Give Turkish Coup Plotters Advice on CNN. HuffingtonPost. Retrieved onhttp://www.huffingtonpost.com/entry/cia-officialsturkey-coupadvice_us_578a2d02e4b08608d334c32c on May 30, 2017.

Papacharissi, Z., \& de Fatima Oliveira, M. (2012). Affective News and Networked Publics: The Rhythms of News Storytelling on \#Egypt. Journal of Communication, 62(2), 266-282.

Pitt, L. F. (2012). Web 2.0, social media and creative consumers-implications for public policy; introduction to the special edition. Journal of Public Affairs (14723891), 12(2), 105-108.

Postman, N. (1985). Amusing Ourselves to Death: Public Discourse in the Age of Show Business. New York, NY: Viking Penguin.

Shirky, C. (2011). The Political Power of Social Media: Technology, the Public Sphere, and Political Change. Foreign Affairs, 90(1), 28-41.

Thompson, K. K. (2011). Not Like an Egyptian: Cybersecurity and the Internet Kill Switch Debate. Texas Law Review, 90(2), 465-495. 
Travis, H. (2013). Wargaming the "Arab Spring": Predicting Likely Outcomes and Planning U.N. Responses. Cornell International Law Journal, 46(2), 75-142.

Tufekci, Z., \& Wilson, C. (2012). Social Media and the Decision to Participate in Political Protest: Observations from Tahrir Square. Journal of Communication, 62(2), 363-379.

Youmans, W., \& York, J. C. (2012). Social Media and the Activist Toolkit: User Agreements, Corporate Interests, and the Information Infrastructure of Modern Social Movements. Journal of Communication, 62(2), 315-329. 